\title{
Measuring medicine-related experiences from the patient perspective: a systematic review
}

\author{
This article was published in the following Dove Press journal: \\ Patient Related Outcome Measures \\ 4 October 2016 \\ Number of times this article has been viewed
}

\section{Barbra Katusiime \\ Sarah Corlett' \\ Joanne Reeve ${ }^{2}$ \\ Janet Krska'}

'Medway School of Pharmacy, The Universities of Kent and Greenwich, Chatham, Maritime, Kent, UK;

${ }^{2}$ Warwick Medical School, University of Warwick, Coventry, UK
Correspondence: Barbra Katusiime Medway School of Pharmacy, The Universities of Kent and Greenwich, Central Avenue, Chatham Maritime, Chatham ME4 4TB, UK

Tel +44I634202920

Email bk23।@kent.ac.uk
Background: There is an increasing drive to measure and so improve patients' experiences and outcomes of health care. This also applies to medicines, given their ubiquity as health care interventions. Patients' experiences of using medicines vary, and instruments which measure these are seen as an essential component to improve care. We aimed to identify generic measures of patients' experiences of using prescription medicines and to examine their properties and suitability for use in research or practice.

Methods: Multiple electronic databases were searched: MEDLINE, Embase, PsycINFO, PsycARTICLES, CINHAL Plus, PROQOLID ${ }^{\circledR}$, and Google Scholar. We identified, critically appraised, and summarized generic questionnaires assessing one or more aspects of the medicine use experience among adult patients using prescription medicines for chronic conditions, and the process of questionnaire development, degree of patient involvement, and/ or validation processes.

Results: Fifteen questionnaires were included. Of these, nine measures were multidimensional, covering various aspects of medicine use. Six instruments covered only a single domain, assessing a specific facet of using medicines. Domains covered were the following: effectiveness; convenience, practicalities, and/or managing medicines; information, knowledge, and/ or understanding; side effects; relationships and/or communication with health professionals; impact on daily living and/or social life; general satisfaction; attitudes; beliefs, concerns, and/or perceptions; medical follow-up and/or adherence-related issues; treatment- and/or medicine-related burden, perceived control, or autonomy; self-confidence about medicine use; availability and accessibility; and medicine-related quality of life. None of the identified questionnaires covered all domains. Instruments varied in the extent of patient involvement in both their development and validation.

Conclusion: There is a scarcity of psychometrically sound, comprehensive, and generic measures of experiences of using prescription medicines among adult patients living with chronic illnesses. There is a need for further development and/or validation of existing instruments suitable for use in this population.

Keywords: prescription medicine, patient experience, questionnaire, patient-reported outcome, development, validation

\section{Introduction}

Prescribing of medicines is one of the most common health care interventions, and monitoring experiences of medicines use is a priority. ${ }^{1}$ With an increasingly aging population, more people are living with multiple chronic illnesses that often demand the use of multiple medicines. ${ }^{2}$ 
Although medicines are beneficial, relieving symptoms, preventing exacerbations, or even prolonging life, having to cope with using regular medicines alongside a long-term illness can be challenging but is poorly understood. Chronic conditions often necessitate complex self-management of both disease effects and medical interventions, which impose substantial demands on a patient's time, effort, and finances. ${ }^{3-6}$ The workload associated with preparing and organizing regular medicine use and other practical difficulties can be burdensome, ${ }^{4}$ while paying for long-term medicines may also cause financial difficulties. ${ }^{7-9}$

Medicine burden, which is one aspect of treatment burden, can lead to nonadherence and poor clinical outcomes, as well as affecting patient satisfaction, psychological wellbeing, social functioning, and quality of life., ${ }^{4,6,10}$ Given the growing numbers of people using long-term medicines for multiple chronic conditions (polypharmacy), ${ }^{11}$ the need to not only understand but also measure this burden is urgent.

Patients' experiences of using medicines vary and are influenced by a range of factors, including the nature and severity of disease condition(s), effectiveness, convenience, and impact on general well-being. ${ }^{12-16}$ Some people are reluctant to use medicines, while others have mixed views through weighing potential harmful effects against overall benefits. ${ }^{12,17}$ Patients may worry about accessibility and availability, medicine-related risks, interactions, or dependence. ${ }^{12,14,16}$ Side effects constitute a significantly burdensome aspect of treatment, ${ }^{4,6}$ which can affect patients' quality of life. ${ }^{10}$ The number of medicines and regimen complexity, including route and frequency of administration, and physical properties (eg, taste or size of tablet), ${ }^{18}$ also impact on patients' experiences.

There is a recognized need for health systems to understand and monitor patients' experiences, to improve the quality of care. ${ }^{19-21}$ Patient-reported experience measures and patient-reported outcome measures are important for helping patients judge how they feel about their own experiences and outcomes of care, including the benefits and risks of treatment. ${ }^{22}$

Tools covering medicines use mainly focus on inappropriate prescribing, ${ }^{23}$ identifying potential medicine-related problems (including adverse drug reactions [ADRs]), ${ }^{24}$ and adherence. ${ }^{25}$ Most of these focus on assessing prescriberdefined outcomes, and hence may not elicit patients' experiences. Moreover, a recent study has shown that patients' day-to-day difficulties with self-care (including medicine use) may be underexplored in practice as clinicians target biomedical problems more than socio-behavioral factors, such as access or social support. ${ }^{26}$
Instruments are available which measure how patients actually use medicines, although not standardized or validated, ${ }^{27}$ as well as assessing individuals' ability to manage medicines. ${ }^{28,29}$ These are usually administered by health professionals or research assistants who assess performance of specific tasks, such as identification of medicines (eg, recognizing packaging or reading the label) and administration or use of medicines. ${ }^{28,29}$ In addition, some use experimental simulations rather than patients' own medicines; actual experiences of organizing and using medicines may differ from those observed in research settings. One comprehensive literature review cited the "lack of a 'gold standard' [measure] for medication management ability". ${ }^{29}$ Furthermore, managing medicines, as one of the most complex activities of daily living, ${ }^{30}$ is only one aspect of the medicine use experience.

Among instruments which do seek patient experiences, measures of satisfaction with treatment dominate the literature. Many instruments focus on disease-specific ${ }^{31-33}$ or treatment-specific measures of satisfaction. ${ }^{34-37}$ However, given the growing prevalence of multi-morbidity, there is an urgent need to understand more about generic measures that are potentially applicable across a range of illnesses and medicines. Several generic instruments have been developed to measure satisfaction with medicines ${ }^{38-40}$ but have recently been criticized as measuring only selected aspects of medicines use. ${ }^{4,41}$ To our knowledge, no reviews covering generic measures of medicine-related experiences and their associated burden have been published. We therefore aimed to identify generic measures of patients' experiences of using prescription medicines, assess their content domains, and summarize their development and/or validation processes.

\section{Methods}

\section{Database search and search strategy}

Multiple electronic databases were searched: MEDLINE, Embase, PsycINFO, PsycARTICLES, CINHAL Plus, and Google Scholar. A manual, free-text, search of the PROQOLID $^{\circledR}$, a specific database that houses several patientrelated measures, was also conducted. Hand-searching of bibliographies of relevant articles was undertaken to identify related articles. A 20-year search period, January 1995 to April 2015, was selected, based on the publication date of an early landmark measure of lay representations and beliefs about prescription medicines, the Beliefs about Medicines Questionnaire (BMQ) ${ }^{42}$ This timeframe ensured that relevant measures developed in the 5 years before publication of the $\mathrm{BMQ}^{42}$ were included. A broad, but sensitive, keyword search strategy was employed to identify studies describing 
the development and/or validation of measures used to assess adults' medicine-related experiences. Categories of search terms were combined in a stepwise fashion, and relevant search filters were applied to specific publication dates. Sample categories and search terms used include 1) "medicine" or "medication" or "drug" or "prescription" and 2) "patient experiences" or "experience*" or "view*" or "perception*" or "attitude*" or "belief" or "concern*". Categories 1 and 2 were crossed with search terms in category 3: "questionnaire" or "instrument" or "tool" or "scale" or "measure" or "survey*" or "self-report" or "patient reported measure" or "develop*" or "valid*". Neither disease conditions nor medicine types were specified. Supplementary material, Additional file 1 provides the full search strategy.

\section{Inclusion and exclusion criteria}

We reviewed studies which involved adults (age $\geq 18$ years) using prescription medicines, as children's ability to selfreport their own experiences differ and instrument development processes may also vary. ${ }^{43}$ Primary research studies using a generic (not disease- or treatment-specific), selfcompletion instrument on any aspect relating to medicine use experiences and describing questionnaire development and/or validation in a target population were included. Articles were published in English. We excluded the following: studies that involved only children or adolescents; studies that primarily reported use of over-the-counter medicines or other therapies (eg, diet, exercise, or any other aspect of self-care); studies that described disease-, product-, and/or device-specific measures; studies that used clinician- or pharmacist-reported tools for drug-related problems; studies that used tools for assessing patients' ability to manage their medicines; studies that described screening tools for assessing inappropriate prescribing; studies that used side effect-/ADR-rating scales; studies that measured satisfaction with pharmaceutical services; studies that primarily assessed adherence; secondary validation studies, except if they reported a revised version of the instrument; cross-cultural (and language) adaptations of eligible questionnaires; and protocols for research.

\section{Article retrieval, data extraction, and analysis}

All study titles and abstracts were reviewed, discarding duplicates. If eligible, the full-text article was scrutinized to check for the questionnaire and/or its items (questions). Additional searches were conducted if the questionnaire was not included in the primary article. Potentially relevant studies were screened for inclusion suitability and discussed among the research team (BK, SC, JK). Data extraction (by $\mathrm{BK}$ ) from eligible articles was checked and supervised (by $\mathrm{SC}, \mathrm{JK}$ ), and regular discussions among all authors were held to resolve any issues. The initial literature search was conducted in April 2015 and updated in November 2015.

A data extraction form was used to collect the studyspecific (sample size, study population and setting, country and language of origin) and questionnaire-specific information (name and purpose, number of items, content domain(s) and/or subscales, type of response scale, mode of administration and recall period if specified). Questionnaire derivation, particularly the extent of direct patient involvement in item generation and testing, and validation methods were reviewed, and psychometric properties, such as reliability and different forms of validity, were assessed in relation to published criteria. ${ }^{44}$ Comparison of instruments included domain coverage, development history, particularly patient involvement in item generation, reliability, and validity. Practical properties, such as completion time, were also examined where available.

Standards and guidance state that documentation of an instrument's development history is fundamental. ${ }^{22,45}$ This includes item generation and testing of how well patients understand questionnaire items and response options and the appropriateness of the measure to the patient group, ${ }^{46,47}$ helping to assess face and content validity, alongside researchers and expert panels. ${ }^{44}$ Records of measurement (or psychometric) properties, particularly reliability and validity, also provide evidence that an instrument measures what it claims. ${ }^{22,44,45}$ Other characteristics, such as mode of questionnaire administration and the time period over which a participant is requested to reflect (recall period), content domains, number of items and their response options, and the population and setting used also impact on instrument validity. ${ }^{45}$

Construct validation of underlying theoretical concepts and domains in a questionnaire can be conducted using different methods, scale analysis (through exploratory and/or confirmatory factor analysis, item-total correlations [adequate if $>0.20]^{48}$ and floor-ceiling effects that explore lowest or highest possible scores) and convergent and discriminant (or divergent) validations, which explore relationships with conceptually similar and dissimilar reference instrument(s), respectively. ${ }^{44,48}$ Correlations $\geq 0.3$ may support convergent validity, whereas a trend of low correlations may infer discriminant validity. ${ }^{48}$ Both convergent and discriminant validations are aspects of criterion-related validation, in which scores of new questionnaires (or those undergoing development) are compared with established ones (or "gold standards"); 
correlations of at least 0.70 with a "gold standard" measure may confirm criterion-related validity. ${ }^{44}$ Other aspects of criterion-related validity, such as predictive validation, test an instrument's ability to predict associations or differences in certain variables in the expected direction. ${ }^{49}$ Known-groups validity examines an instrument's ability to differentiate cohorts of patients with well-known characteristics. ${ }^{48}$

\section{Results}

\section{Identified generic measures of medicine} use experiences

Fifteen articles described the development and/or validation of generic measures relating to the experience of using prescription medicines among adult patients.

Of these, nine were multi-domain (three to ten domains), five of which examined satisfaction with different aspects of using medicines: three versions of the Treatment Satisfaction Questionnaire for Medication (TSQM; TSQM version 1.4, ${ }^{39}$ TSQM II, ${ }^{38}$ and TSQM- $\left.9^{50}\right)$, the Treatment Satisfaction with Medicines Questionnaire (SATMED- $\mathrm{Q}^{40}$ ), and the Patient Satisfaction with Medication Management instrument $\left(\mathrm{PSMM}^{51}\right)$. Other multi-domain instruments were the Drug Therapy Concerns Questionnaire (DTC ${ }^{52}$ ), the Okere-Reiner Survey, ${ }^{53}$ the Living with Medicines Questionnaire $\left(\mathrm{LMQ}^{54}\right)$, and the Patient-Reported Outcomes Measure of Pharmaceutical Therapy for Quality of Life (PROMPT-QoL ${ }^{41}$ ).

Six instruments covered only one domain, although some of these were divided into subscales by statistical analyses: a unidimensional measure of treatment burden (the Treatment Burden Questionnaire $[\mathrm{TBQ}]^{55}$ ), a questionnaire assessing patients' attitudes to deprescribing or medicine cessation (Patients' Attitudes Towards Deprescribing $[\mathrm{PATD}]^{56}$ ), the $\mathrm{BMQ}^{42}$, a measure of perceived sensitivity to medicines (Perceived Sensitivity to Medicines questionnaire $[\mathrm{PSM}]^{57}$ ), the Satisfaction with Information about Medicines Scale $\left(\mathrm{SIMS}^{58}\right)$, and questionnaires measuring doctor-patient communication about medicines. ${ }^{59}$

Most of the questionnaires identified were self-administered on 3- to 10-point Likert-type scales. All instruments were multi-item, ranging from five to 60 items per questionnaire. The majority were developed in English, originating from the UK, USA, and Australia, with only three ${ }^{40,41,55}$ from non-English-speaking countries: Spain, Thailand and France. Table 1 summarizes the characteristics of the 15 instruments.

\section{Content domains}

The 15 instruments covered a wide range of domains (Table 2), described by authors as the following: effectiveness;

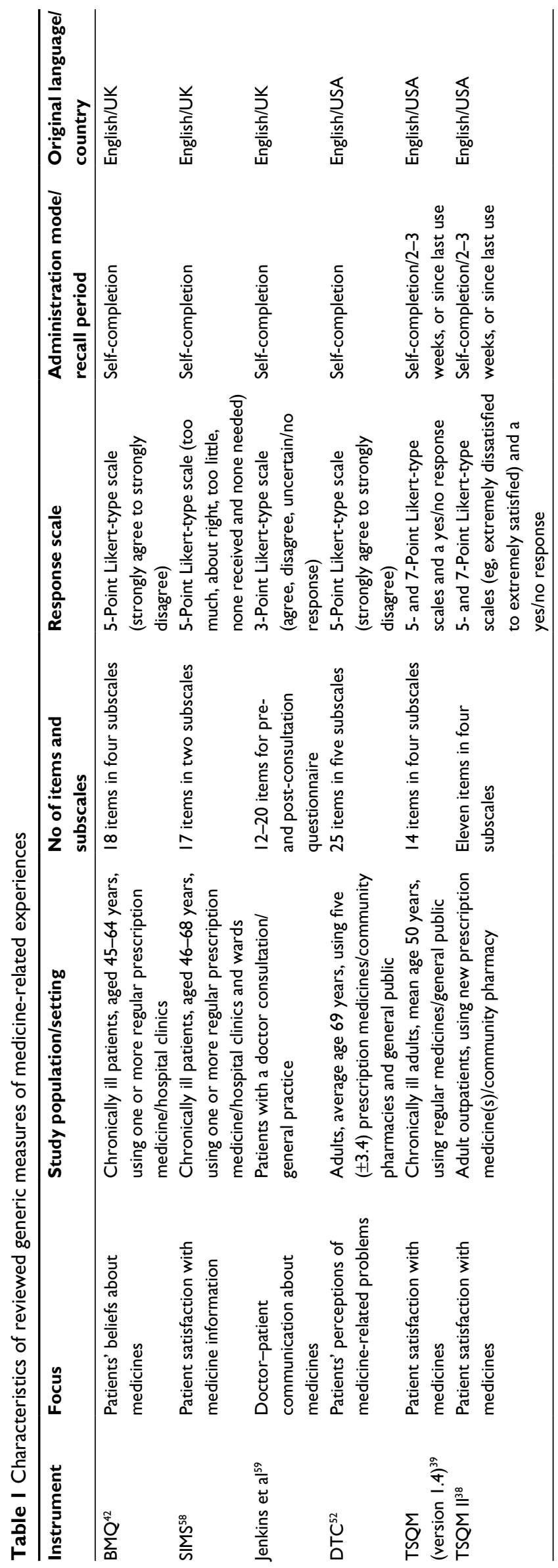




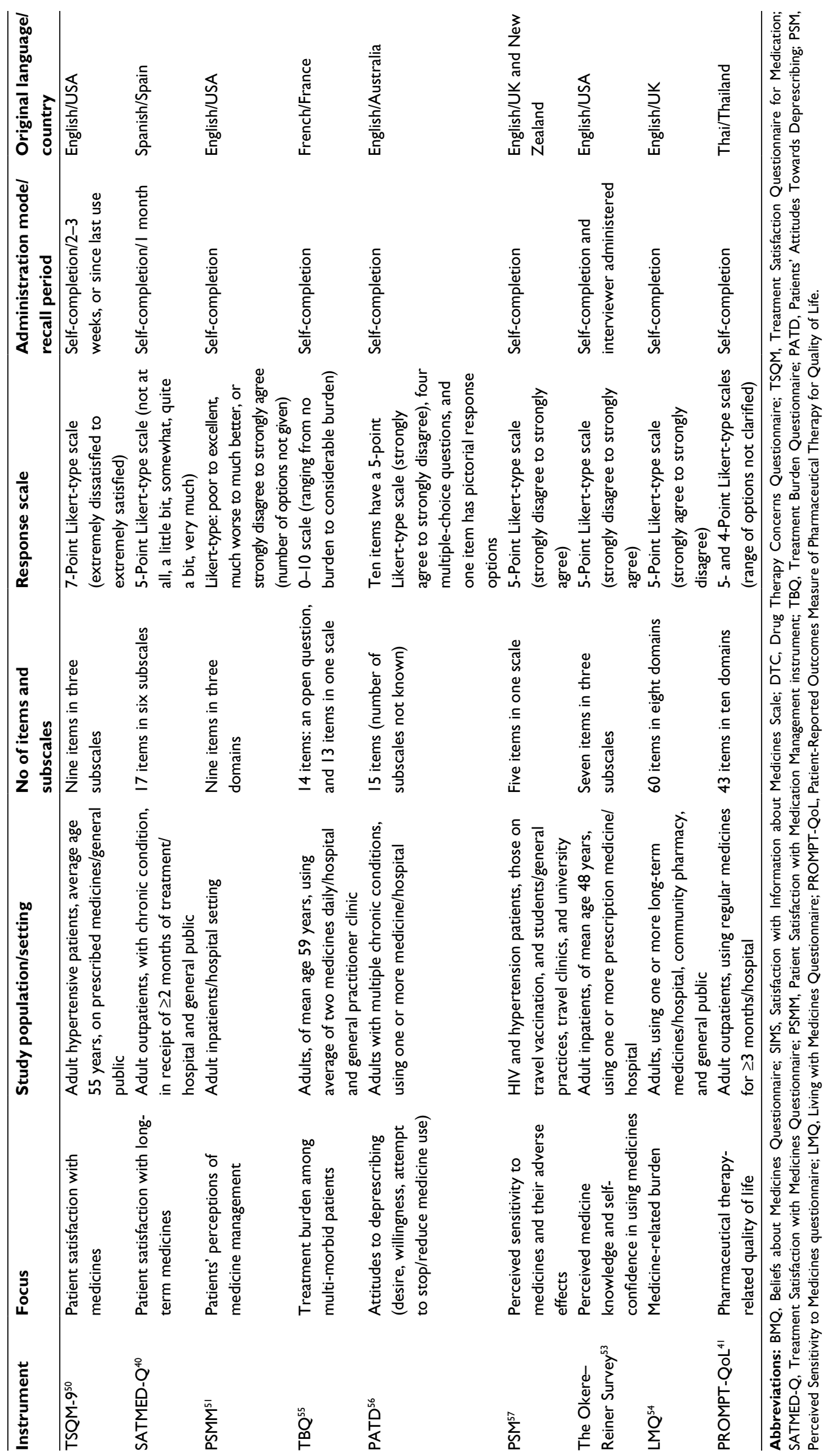




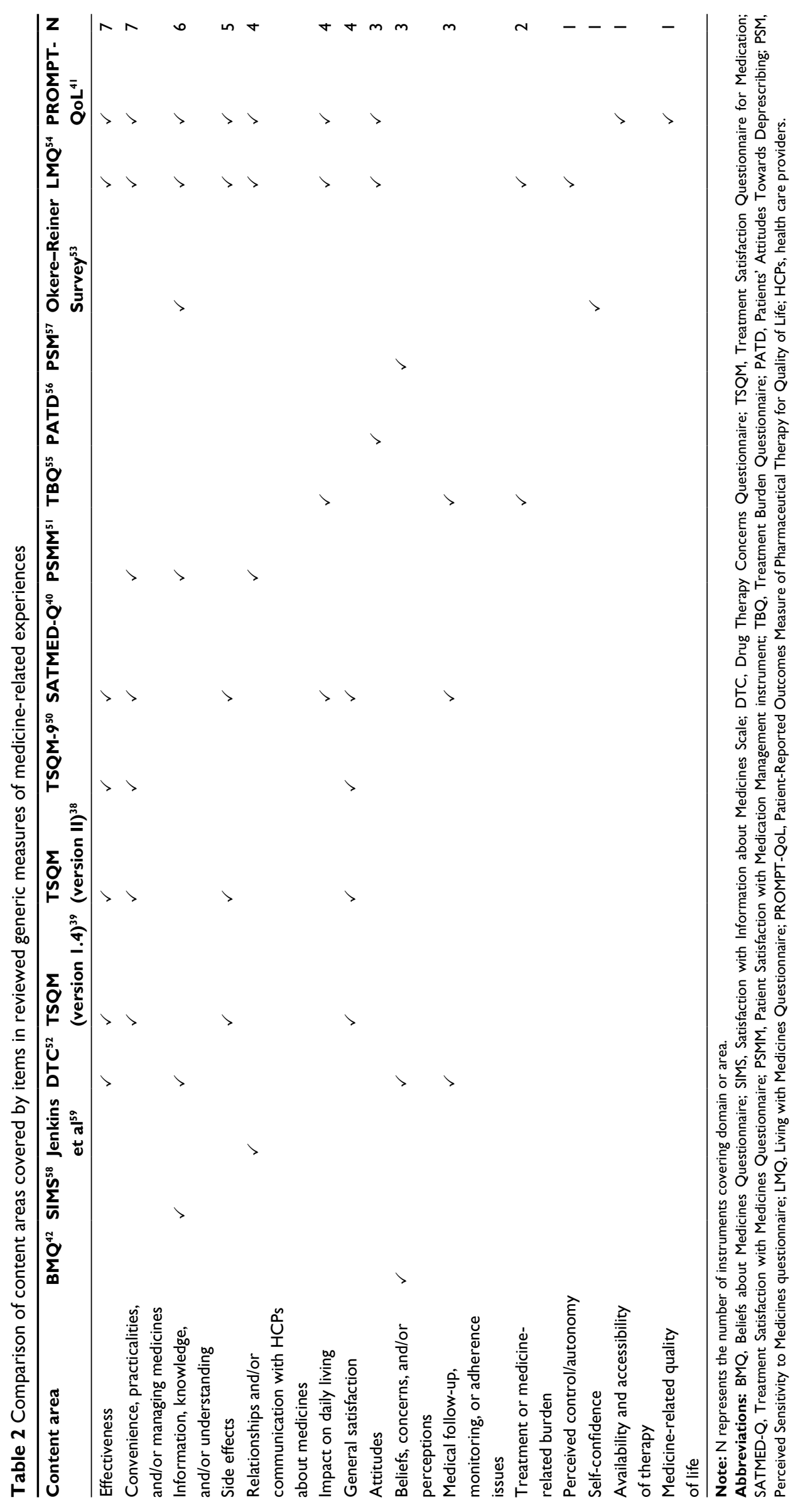


convenience, practicalities, and/or managing medicines; information, knowledge, and/or understanding; side effects; relationships and/or communication with health professionals; impact on daily living and/or social life; general satisfaction; attitudes; beliefs, concerns, and/or perceptions; medical follow-up and/or adherence-related issues; treatment- and/ or medicine-related burden, perceived control, or autonomy; self-confidence about medicine use; availability and accessibility; and medicine-related quality of life. These probably reflect most issues that affect people using regular medicines.

\section{Patient involvement in item generation}

For the majority of instruments, item generation was based on the literature. Some incorporated patients' views but indirectly. Only seven measures had evidence of being developed using direct patient input: five employed patient interviews as the primary source of questionnaire items (BMQ $,{ }^{42} \mathrm{PSMM},{ }^{51}$ TBQ ${ }^{55} \mathrm{LMQ},{ }^{54}$ and PROMPT-QoL ${ }^{41}$ ) and two focus groups (SATMED-Q ${ }^{40}$ and TSQM version $1.4^{39}$ ). Several were judged to emphasize the perspective/opinions of researchers or health professionals over those of patients (Jenkins' instrument, ${ }^{59}$ SIMS,${ }^{58}$ and DTC ${ }^{52}$ ). Table 3 compares the different methods employed in item generation and testing.

\section{Reliability}

The vast majority of instruments were assessed for internal consistency (Table 4), mostly using Cronbach's alpha with some reporting test-retest reliability as intra-class correlation coefficient and correlation coefficients $(r)$; values $\geq 0.7$, obtained from a sample size of at least 50 patients, are advisable. ${ }^{44}$ One study ${ }^{41}$ employed Rasch analysis to estimate person and item reliabilities (acceptable values $>0.8$ and 0.9 , respectively), which assess an instrument's ability to distinguish between high and low patient scores and the level of item difficulty, respectively. ${ }^{60}$

\section{Scale analysis and construct validity}

Most instruments employed exploratory techniques for scale analysis (Table 4). However, only a few employed confirmatory methods ascertaining underlying content domains and/or their relationships: TSQM II, TSQM-9, SATMED-Q, BMQ, and the Okere-Reiner Survey.

\section{Criterion-related, convergence, and/or discriminant validity}

Criterion-related, convergence, and/or discriminant validity were variably reported by only eight instruments: TSQM (version 1.4), TSQM II, SATMED-Q, TBQ, SIMS, BMQ,

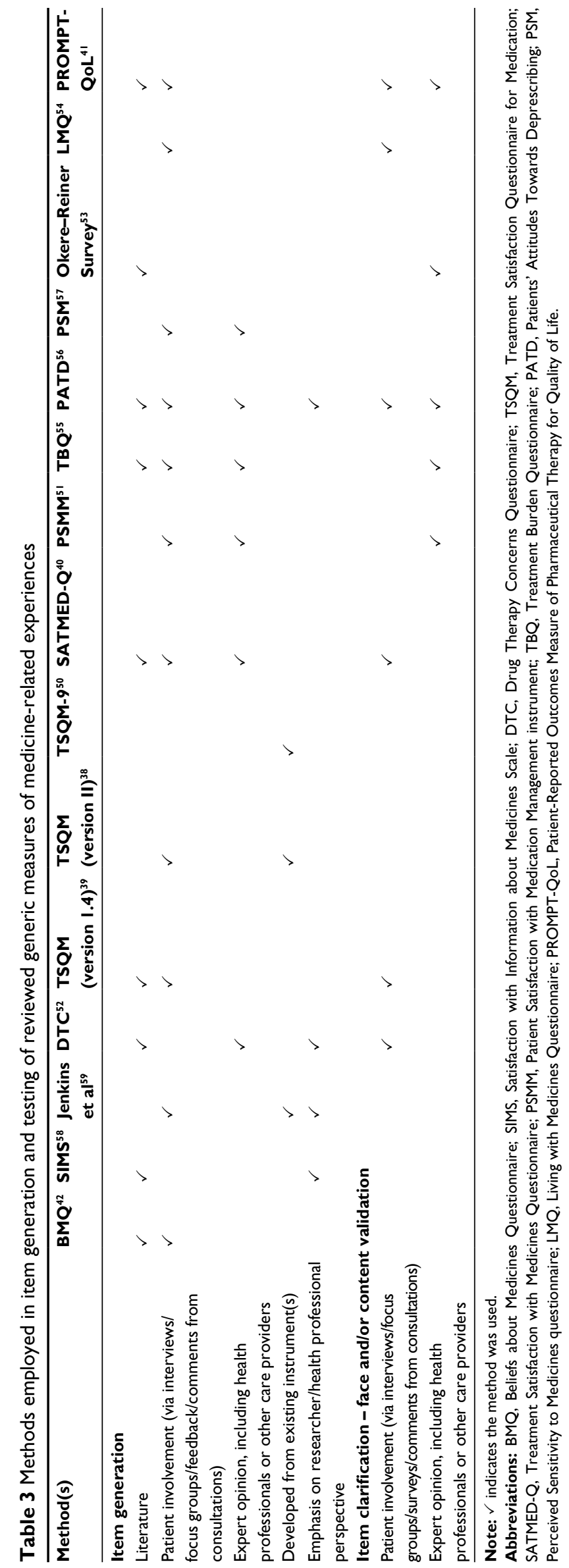




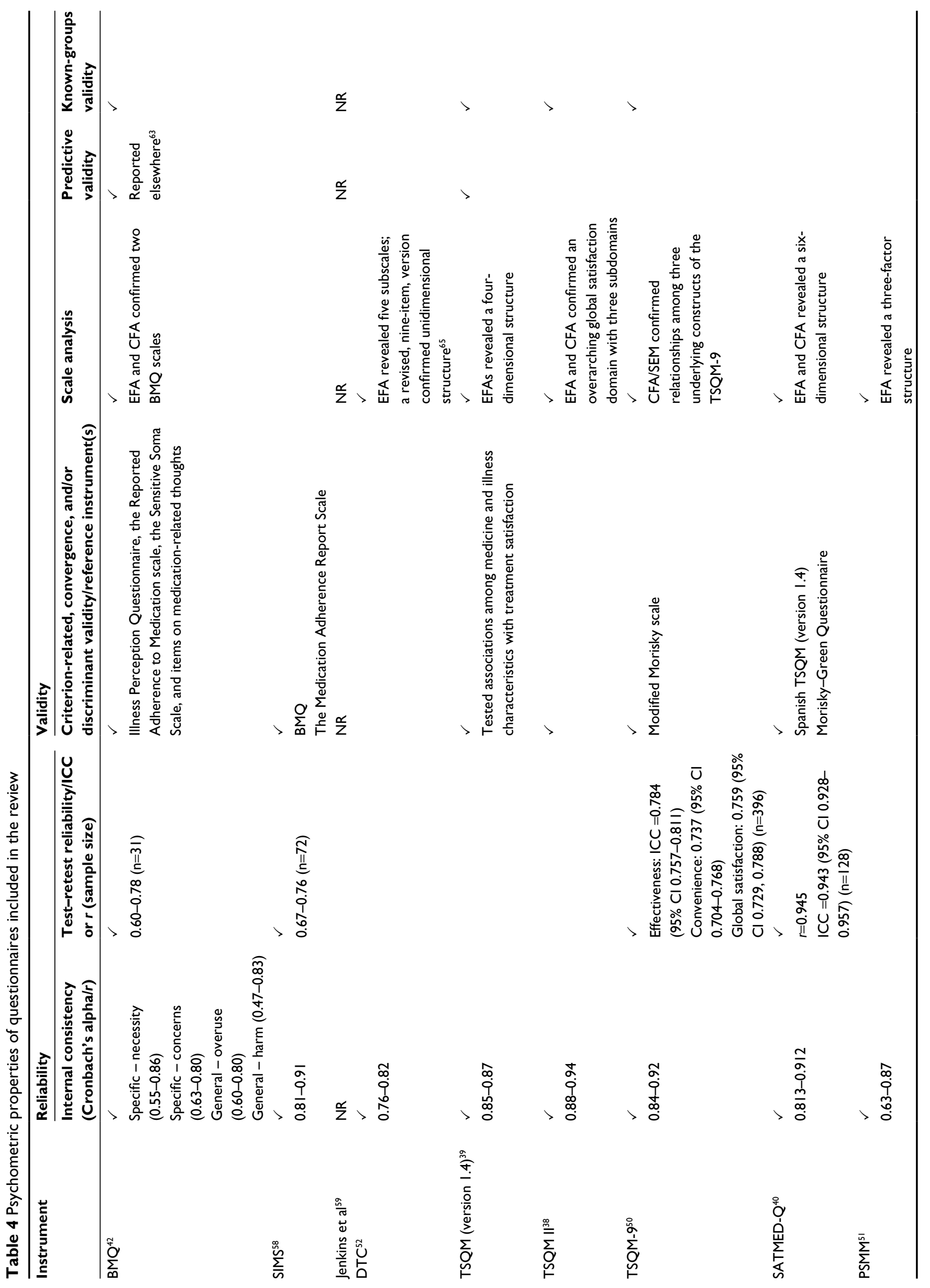




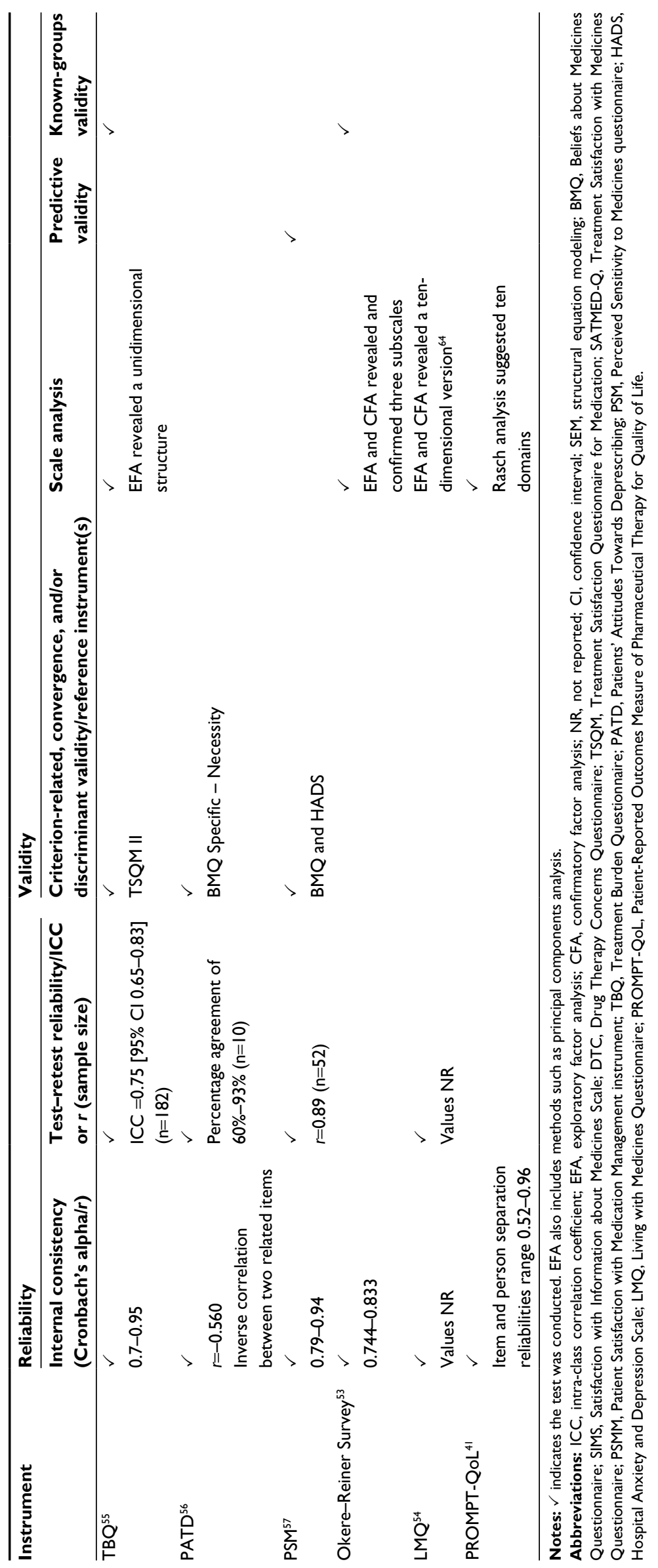


PSM, and PATD (Table 4). The $\mathrm{BMQ}^{42}$ and earlier versions of the TSQM ${ }^{38,39}$ were the most commonly used criterionreferenced instruments. For instance, in validating the SIMS, patients with stronger concerns about medicines as measured by the BMQ were more likely to be less satisfied with their medicine information. Patients with more medicine-related concerns, or beliefs about harm, were reported to not only be less trustful of their medicines but also desire alterations to their regimes or avoid them. ${ }^{42}$ In development of the PSM scale, scores on the "concerns" subscale of the BMQ, indicating negative beliefs about medicines, were significantly associated with perceived sensitivity to medicines ( $r=0.5, P<0.001)$. Negative moderate correlations $(r=-0.56$, $P<0.001)$ were reported between scores on BMQ items relating to "necessity of current medications" and scores on the PATD. However, the sample size used in this study $(n=51)$ was inadequate to validate the measure of patient attitudes to medicine cessation.

Ruiz et al examined associations between SATMED-Q scores and the Spanish version of the TSQM (version 1.4); significant correlations (range $0.58-0.68, P<0.0005$ ) were reported between subscales assessing similar domains: treatment effectiveness, side effects, convenience, and global satisfaction. ${ }^{40}$ During validation of the TBQ, Tran et al established a negative relationship between treatment burden and treatment satisfaction assessed using the TSQM II: ${ }^{55}$ moderate negative correlations between TBQ scores and TSQM global satisfaction and convenience subscales ( $r=-0.41$ and $r=-0.53$, respectively) and weak negative correlations ( $r=-0.26$ ) between TBQ scores and TSQM efficacy subscale. Treatment burden was significantly higher among patients who had experienced side effects compared to those who had not.

Satisfaction with medicines is positively associated with adherence. ${ }^{50}$ While validating the TSQM-9, moderate correlations (range 0.34-0.46) were reported between convenience, effectiveness, and global satisfaction TSQM-9 subscale scores, and the modified Morisky scale, ${ }^{61}$ which measures adherence. Weak correlations (range 0.09-0.22) were reported between SATMED-Q scores and MoriskyGreen adherence questionnaire scores, ${ }^{62}$ several failing to reach statistical significance.

\section{Known-groups and predictive validity}

Known-groups validity was reported for six measures: BMQ, TSQM version 1.4, TSQM II, TSQM-9, TBQ, and the Okere-Reiner Survey (Table 4). The Okere-Reiner Survey was reported to "clearly distinguish between patients with good and poor perceived knowledge or confidence or satisfaction". ${ }^{53}$ Least reported was predictive validity (Table 4). The BMQ was reported to adequately distinguish patients with different illnesses and treatments ${ }^{42}$ and to predict adherence to therapy. ${ }^{63}$ In validating the TSQM (version 1.4), Atkinson et al tested associations between medicine types and routes of administration and satisfaction levels on all four subscales; patients using parenteral medicines were least satisfied with convenience and side effects, while oral medicines were rated highly on overall satisfaction and convenience. ${ }^{39}$ Similarly, Ruiz et al reported significantly lower satisfaction for convenience for parenteral routes of administration compared to oral and inhalation routes. ${ }^{40}$ Treatment satisfaction assessed by TSQM-9 was significantly greater among "medium compliers", measured by the modified Morisky scale, ${ }^{61}$ compared to "low compliers" $(P<0.0001)$. Tran et al reported significantly higher scores among patients with high treatment burden, measured by the TBQ, compared to those with low or moderate treatment burden, on specific items relating to treatment workload. ${ }^{55}$ Patients with "high burden" needed an average of 43 minutes/week to organize their medicines compared to 17 minutes/week required by "low-burden" patients $(P<0.0001) .{ }^{55}$

\section{Summary}

Of the 15 generic measures of medicine-related experiences, six covered multiple domains and were developed with direct patient involvement, particularly in the item generation phase, tested for any forms of reliability (as internal consistency, test-test, and/or person/item reliability), and/or attempted to confirm construct validity by any means. These were TSQM (including the 14-item, eleven-item, and nine-item versions), SATMED-Q, PROMPT-QoL, and LMQ. However, validity was reported using different methods and to different extents for all these measures, and most authors acknowledge the need for further developmental and/or validation work. The two broadest, patient-generated, multi-domain measures, the PROMPT-QoL ${ }^{41}$ and the LMQ, ${ }^{54,64}$ may provide insight into measurement of multiple, albeit complex, issues surrounding regular medicine use; however, both require further psychometric testing (and/or cross-cultural adaptation) for potential use in research or practice. None of the identified questionnaires covered all domains or considered potential financial burden of medicines in-depth.

The remaining instruments cover single domains or have limited patient involvement in development. The BMQ,${ }^{42}$ one of the earliest measures of beliefs about medicines, has been used widely to understand many aspects of medicine use, 
especially adherence-related behavior. The DTC ${ }^{52,65}$ serves as a potentially useful tool for eliciting patients' perceptions and concerns about medicine-related problems; however, it lacked patient involvement in item generation phases of its development. The domain-specific PSM scale ${ }^{57}$ may be useful for studies evaluating concerns about potential adverse effects of medicines. The Okere-Reiner Survey ${ }^{53}$ is a short measure of patients' knowledge and self-confidence with medicine use, the latter aspect not being included in other instruments, which play an important role in the medicine use experience; however, it was not derived directly from patients despite testing instrument reliability and validity. The PSMM, ${ }^{51}$ an instrument reported to measure patients' perceptions of medicine management, is prescriber-centered and focused on service evaluation, despite being derived directly from patient interviews and including relevant issues. For instance, it considers the practicalities of managing regularly used medicines while in hospital, medicine information, and understanding and patient-provider communication about medicines. The latter aspect was the subject of the scale developed by Jenkins et al. ${ }^{59}$ The PATD questionnaire ${ }^{56}$ considers deprescribing (medicine cessation), and may be used to gain insight into patient preferences or dissatisfaction with medicine regimes; however, further validation of this instrument is also necessary, as it was developed from the perspective of health professionals and evaluated in only a few patients. Although domain-specific and not solely focused on medicine-therapeutic interventions, the TBQ ${ }^{55}$ is potentially useful in assessing treatment burden among multi-morbid patients.

\section{Discussion}

To our knowledge, this is the first review of generic measures of adult patients' experiences of using prescription medicines. Most of the 15 instruments identified could potentially be used in patients with multi-morbidity, using a wide range of medicines, allowing comparison of experiences across different patient groups. However, those which instruct respondents to focus only on one medicine ${ }^{40}$ would require modification. Only a few directly involved patients in item generation, and further validation work is needed, particularly for those instruments covering multidimensional aspects of medicine use.

Collectively, the domains covered probably reflect most issues that affect people using regular medicines. However, none covered all domains, which is important if a whole patient-centered understanding of medicine experiences is to be quantified. Notably, none of the instruments considered the potential financial burden of using prescription medicines in any depth. One of the broad instruments, PROMPT-QoL, includes one item on "medication and travel expenses"41 which is limited as an assessment of cost-related burden. An item in the PATD questionnaire, "having to pay for less medications would play a role in my willingness to stop one or more of my medications", only focuses on cost-related cessation. ${ }^{56}$ One recently developed, ten-item, domainspecific measure of cost-related medicine burden in the US population $^{8}$ explores this issue in isolation. However, it was not included in this review as half the statements relate to nonadherence (eg, cost-related delays in refilling prescriptions and skipping or reducing doses).$^{8}$ There remains a need for instruments that incorporate and assess cost-related issues alongside other dimensions of the medicine use experience.

Overall satisfaction with medicines could be regarded as a potentially key, overarching domain, which is influenced by many of the other domains covered by these instruments and was the main focus of several questionnaires. Of the generic instruments, TSQM (version 1.4 and II) ${ }^{38,39}$ and SATMED-Q ${ }^{40}$ seem promising for evaluating aspects of medicine use which impact on satisfaction. However, both have been criticized as circumscribed and lacking in "psychological domains, such as worry, fear, or concerns", relating to the medicine use experience, ${ }^{41}$ which are covered by the broader instruments.

Patient satisfaction with treatment (and medicines) is positively associated with persistence and adherence to therapy ${ }^{66}$ but negatively associated with treatment burden. ${ }^{55}$ Lifelong medicine use can be burdensome to some patients, ${ }^{13-15}$ and may impact negatively on health-related quality of life. Research attempting to describe the burden (or negative experience) of using medicines has done so under the "umbrella" of treatment burden, ${ }^{4,6,67,68}$ which may represent unshared patient experiences that are not fully addressed during consultations. ${ }^{26}$ However, measures of treatment burden are currently limited, as reported in a review by Eton et al. ${ }^{5}$ In contrast to the present review, Eton et al focused on the overall burden of health care activities, particularly patients' workload of self-care. An instrument addressing the need for such a measure, the TBQ,${ }^{55}$ includes some aspects of medicine-related burden, as well as impact or restriction of daily activities and social life. Other potentially useful multi-domain measures of medicine burden are the LMQ, which is still undergoing development in the $\mathrm{UK},{ }^{54}$ and the PROMPT-QoL, ${ }^{41}$ which also requires further psychometric testing.

Communication and relationships with health care providers was an aspect of medicines use included in a number 
of instruments, including the two broadest, patient-centered measures, PROMPT-QoL ${ }^{41}$ and LMQ, ${ }^{54}$ emphasizing the potential contribution of this domain to satisfaction and treatment burden. The PSMM questionnaire ${ }^{51}$ also includes patient-provider communication problems, for instance, perceived patient burden following repetitive questioning about medicine history, often by multiple providers, and ineffective flow of medicine-related information among health professionals. ${ }^{53}$ Most measures of patient satisfaction with consultations and patient-provider relationships ${ }^{69-71}$ do not focus on medicine-related communication; hence, the instrument developed by Jenkins et al is potentially valuable as a single-domain measure. ${ }^{59}$ Two other instruments, the SIMS $^{58}$ and the Okere-Reiner Survey, ${ }^{53}$ also cover medicines information transfer. The SIMS focuses on this exclusively and is founded on pharmaceutical industry literature, with minimal patient involvement, while the Okere-Reiner Survey measures medicine-related knowledge and understanding but again had little patient involvement during its development.

Many other instruments reviewed were essentially unidimensional, with variable patient involvement in development. The BMQ, which assesses psychological beliefs and concerns about the necessity and safety of medicines, ${ }^{42}$ has been extensively used in adherence-related studies. ${ }^{72,73}$ The PSM scale covers only patient concerns about potential adverse effects of medicines, ${ }^{57}$ while the PATD was developed to measure patients' attitudes to cessation of medicines, ${ }^{56}$ and thus seeks to predict behavior, rather than measure experiences. Like most instruments assessing inappropriate prescribing, ${ }^{23}$ the PATD questionnaire development seemed to emphasize the clinician perspective, rather than the patient perspective. Moreover, deprescribing itself is criticized as a cliniciandriven agenda, which aims to reduce medicine usage and health-system costs. ${ }^{74,75}$ The DTC is broader, including concerns about ADRs, as well as regimen complexity, overmedication, and use of prescription medicines, ${ }^{52}$ but also based on the clinician perspective.

A further instrument, developed in Taiwan and published since the literature review was completed, claims to measure Medication-Related Quality of Life, ${ }^{76}$ a term originally adopted for the LMQ. ${ }^{77}$ This instrument was developed based on subjective well-being scales plus patient interviews and consists of 14 items, covering only three domains: role limitations, self-control, and vitality. ${ }^{76}$ Only the first of these relates directly to medicines burden, as discussed in this review; therefore, this instrument too is limited.

Most instruments included in this review were developed and tested in a specific language and in specific demographic settings, and with some exceptions, have not been tested in other situations. Therefore, cross-cultural adaptations and/ or further testing may be required prior to use in particular clinical or research settings. Given the psychometric properties of the reviewed instruments, there is a need for further development and/or validation of the existing multidimensional, generic, patient-generated, measures of experiences of using prescription medicines among adult patients living with chronic illness.

\section{Implications for research and practice}

Multidimensional, generic, patient-generated measures are essential to evaluate the impact of interventions designed to reduce treatment burden or improve experiences, particularly in the context of multi-morbidity and complex medicines regimes. Such measures could facilitate the identification of patients who find using long-term medicines a challenging experience. This could enable health care professionals to offer tailored support or to more effectively agree treatment tailored to patients' needs. However, little is known about the use of most of these instruments in clinical practice. There is therefore a need to identify and fully validate the best available patient-generated instruments, to facilitate such use. Should a need to develop and test new instruments arise, adding key, albeit deficient, content domains to existing multidimensional measures may support a more comprehensive assessment of medicine use experiences among those living with chronic illness.

\section{Limitations}

Owing to the heterogeneity of studies and reported results, data could neither be evaluated methodologically (as with most systematic reviews) nor be collated for meta-analysis. Although we used relevant guidelines to critique the reported measurement properties of questionnaires, ${ }^{44}$ we did not set out to report an overall quality score for the instruments and their methodological study designs, particularly as many of the instruments were developed long before the recently recommended quality-scoring criteria. ${ }^{78-80}$ Therefore, this review employed a descriptive style to compare characteristics, content areas, and questionnaire derivation and validation processes across reviewed measures. It excluded all disease-, product-, and/or device-specific instruments, pharmaceutical service evaluations, clinician- and pharmacist-led screening tools for medicine-related problems, including ADRs, tools assessing patients' abilities to manage medicines, adherencefocused tools, and cross-cultural adaptations of eligible questionnaires, even though they may have considered key aspects 
of the medicine use experience. It did include measures of satisfaction with various aspects of medicine use, despite concerns that measuring patients' experiences in terms of satisfaction may introduce acquiescence bias. Although an organized and broad literature search was conducted across multiple databases, it is possible that a few generic instruments reporting certain aspects of medicine-related experiences may have been missed. Appropriate search strategies were designed to minimize the likelihood of this.

\section{Conclusion}

There is a scarcity of generic, patient-generated, psychometrically sound, comprehensive measures of the medicine use experiences of adult patients. Moreover, there is insufficient evidence for the routine use of existing measures in clinical practice. Therefore, there is a need for further development and/or validation of existing patient-derived, multi-domain instruments. In addition to their use in research, such tools may help individual patients to identify a range of medicinerelated issues that impact on their day-to-day life and thus facilitate conversations with health providers in addressing those issues.

\section{Acknowledgments}

This work was supported by the Medway School of Pharmacy, The Universities of Kent and Greenwich, as part of a $\mathrm{PhD}$ program, and by an award from the Commonwealth Scholarship Commission in the UK funded by the UK government.

\section{Author contributions}

All authors conceived the study. BK conducted the literature searches and drafted early versions of the manuscript. All authors contributed toward data analysis, drafting and critically revising the paper and agree to be accountable for all aspects of the work.

\section{Disclosure}

The authors report no conflicts of interest in this work.

\section{References}

1. Royal Pharmaceutical Society [homepage on the Internet]. Medicines optimisation: helping patients to make the most of medicines. Good practice guidance for healthcare professionals in England. 2013. Available from: http://www.rpharms.com/promoting-pharmacy-pdfs/helpingpatients-make-the-most-of-their-medicines.pdf. Accessed August 26, 2015.

2. Guthrie B, Makubate B, Hernandez-Santiago V, Dreischulte T. The rising tide of polypharmacy and drug-drug interactions: population database analysis 1995-2010. BMC Med. 2015;13(1):1-10.
3. GallacherK, May CR, MontoriVM, MairFS. Understanding patients'experiences of treatment burden in chronic heart failure using normalization process theory. Ann Fam Med. 2011;9(3):235-243.

4. Eton D, Ridgeway J, Egginton J, et al. Finalizing a measurement framework for the burden of treatment in complex patients with chronic conditions. Patient Relat Outcome Meas. 2015;6:117-126.

5. Eton DT, Elraiyah TA, Yost KJ, et al. A systematic review of patientreported measures of burden of treatment in three chronic diseases. Patient Relat Outcome Meas. 2013;4:7-20.

6. Sav A, King MA, Whitty JA, et al. Burden of treatment for chronic illness: a concept analysis and review of the literature. Health Expect. 2015;18(3): 312-324.

7. Schafheutle EI. Patients' views on the UK policy of prescription chargesinsights from qualitative interviews. Res Social Adm Pharm. 2008;4(4): 343-354.

8. Burcu M,Alexander GC, Ng X, Harrington D. Construct validity and factor structure of survey-based assessment of cost-related medication burden. Med Care. 2015;53(2):199-206.

9. Whitty JA, Sav A, Kelly F, et al. Chronic conditions, financial burden and pharmaceutical pricing: insights from Australian consumers. Aust Health Rev. 2014;38(5):589-595.

10. Murawski MM, Bentley JP. Pharmaceutical therapy-related quality of life: conceptual development. $J$ Soc Adm Pharm. 2001;18(1):2-14.

11. Barnett NL, Oboh L. When less is more: the challenge of polypharmacy. Eur J Hosp Pharm Sci Pract. 2014;21(1):63-64.

12. Pound P, Britten N, Morgan M, et al. Resisting medicines: a synthesis of qualitative studies of medicine taking. Soc Sci Med. 2005;61(1): $133-155$.

13. May C,MontoriVM,MairFS. Weneed minimally disruptivemedicine. $B M J$. 2009;339:b2803.

14. Krska J, Morecroft CW, Poole H, Rowe PH. Issues potentially affecting quality of life arising from long-term medicines use: a qualitative study. Int J Clin Pharm. 2013;35(6):1161-1169.

15. Sav A, Kendall E, McMillan SS, et al. 'You say treatment, I say hard work': treatment burden among people with chronic illness and their carers in Australia. Health Soc Care Community. 2013;21(6): 665-674.

16. Britten N. Medicines and Society: Patients, Professionals and the Dominance of Pharmaceuticals. 1st ed. Hampshire: Palgrave Macmillan; 2008.

17. Moen J, Bohm A, Tillenius T, Antonov K, Nilsson JL, Ring L. "I don't know how many of these [medicines] are necessary.." - a focus group study among elderly users of multiple medicines. Patient Educ Couns. 2009;74(2): $135-141$.

18. Ingersoll KS, Cohen J. The impact of medication regimen factors on adherence to chronic treatment: a review of literature. J Behav Med. 2008;31(3):213-224.

19. Devlin N, Appleby J. Getting the Most out of PROMs: Putting Health Outcomes at the Heart of NHS Decision-Making. 1st ed. London: The King's Fund; 2010.

20. Schoen C, Osborn R, Doty MM, Bishop M, Peugh J, Murukutla N. Toward higher-performance health systems: adults' health care experiences in seven countries, 2007. Health Aff (Millwood). 2007;26(6): w717-w734.

21. NHS England [homepage on the Internet]. Health and high quality care for all, now and for future generations. NHS England welcomes publishing of medicines optimisation [updated May 2, 2013]. Available from: http:// www.england.nhs.uk/2013/05/02/med-opt/. Accessed November 27, 2014.

22. Speight J, Barendse SM. FDA guidance on patient reported outcomes. BMJ. 2010;340:c2921.

23. Kaufmann CP, Tremp R, Hersberger KE, Lampert ML. Inappropriate prescribing: a systematic overview of published assessment tools. Eur J Clin Pharmacol. 2013;70(1):1-11.

24. Jarernsiripornkul N, Krska J, Capps P, Richards R, Lee A. Patient reporting of potential adverse drug reactions: a methodological study. $\mathrm{Br} \mathrm{J}$ Clin Pharmacol. 2002;53(3):318-325. 
25. Garfield S, Clifford S, Eliasson L, Barber N, Willson A. Suitability of measures of self-reported medication adherence for routine clinical use: a systematic review. BMC Med Res Methodol. 2011;11(1):149.

26. Bohlen K, Scoville E, Shippee ND, May CR, Montori VM. Overwhelmed patients: a videographic analysis of how patients with type 2 diabetes and clinicians articulate and address treatment burden during clinical encounters. Diabetes Care. 2012;35(1):47-49.

27. Paterson $\mathrm{C}$, Britten N. A narrative review shows the unvalidated use of self-report questionnaires for individual medication as outcome measures. J Clin Epidemiol. 2005;58(10):967-973.

28. Farris KB, Phillips BB. Instruments assessing capacity to manage medications. Ann Pharmacother. 2008;42(7):1026-1036.

29. Elliott RA, Marriott JL. Standardised assessment of patients' capacity to manage medications: a systematic review of published instruments. BMC Geriatr. 2009;9(1):27.

30. Zartman AL, Hilsabeck RC, Guarnaccia CA, Houtz A. The pillbox test: an ecological measure of executive functioning and estimate of medication management abilities. Arch Clin Neuropsychol. 2013;28(4): 307-319.

31. Worth A, Hammersley VS, Nurmatov U, Sheikh A. Systematic literature review and evaluation of patient reported outcome measures (PROMs) for asthma and related allergic diseases. Prim Care Respir J. 2012; 21(4):455-458.

32. Gibbons E, Casañas i Comabella C, Fitzpatrick R. A structured review of patient-reported outcome measures for patients with skin cancer, 2013. Br J Dermatol. 2013;168(6):1176-1186.

33. Bates A, Davis C, Takwale A, Knepil G. Patient-reported outcome measures in nonmelanoma skin cancer of the face: a systematic review. $\mathrm{BrJ}$ Dermatol. 2013;168(6):1187-1194.

34. Campbell JL, Kiebert GM, Partridge MR. Development of the satisfaction with inhaled asthma treatment questionnaire. Eur Respir J. 2003;22(1): 127-134.

35. Rofail D, Gray R, Gournay K. The development and internal consistency of the Satisfaction with Antipsychotic Medication scale. Psychol Med. 2005;35(7):1063-1072.

36. Anderson RT, Skovlund SE, Marrero D, et al. Development and validation of the insulin treatment satisfaction questionnaire. Clin Ther. 2004;26(4): 565-578.

37. Brod M, Hammer M, Christensen T, Lessard S, Bushnell D. Understanding and assessing the impact of treatment in diabetes: the TreatmentRelated Impact Measures for Diabetes and Devices (TRIM-Diabetes and TRIM-Diabetes Device). Health Qual Life Outcomes. 2009;7:83.

38. Atkinson MJ, Kumar R, Cappelleri JC, Hass SL. Hierarchical construct validity of the treatment satisfaction questionnaire for medication (TSQM version II) among outpatient pharmacy consumers. Value Health. 2005;8 Suppl 1:S9-S24.

39. Atkinson MJ, Sinha A, Hass SL, et al. Validation of a general measure of treatment satisfaction, the Treatment Satisfaction Questionnaire for Medication (TSQM), using a national panel study of chronic disease. Health Qual Life Outcomes. 2004;2(1):12.

40. Ruiz MA, Pardo A, Rejas J, Soto J, Villasante F, Aranguren JL. Development and validation of the "Treatment Satisfaction with Medicines Questionnaire” (SATMED-Q). Value Health. 2008;11(5):913-926.

41. Sakthong P, Suksanga P, Sakulbumrungsil R, Winit-Watjana W. Development of patient-reported outcomes measure of pharmaceutical therapy for quality of life (PROMPT-QoL): a novel instrument for medication management. Res Social Adm Pharm. 2015;11(3):315-338.

42. Horne R, Weinman J, Hankins M. The beliefs about medicines questionnaire: the development and evaluation of a new method for assessing the cognitive representation of medication. Psychol Health. 1999;14(1): $1-24$.

43. Worth A, Hammersley V, Knibb R, et al. Patient-reported outcome measures for asthma: a systematic review. NPJ Prim Care Respir Med. 2014; 24:14020.

44. Terwee CB, Bot SDM, de Boer MR, et al. Quality criteria were proposed for measurement properties of health status questionnaires. $J$ Clin Epidemiol. 2007;60(1):34-42.
45. US Department of Health and Human Services Food and Drug Administration. Guidance for industry: patient-reported outcome measures: use in medical product development to support labeling claims. 2009. Available from: www.fda.gov/downloads/Drugs/GuidanceComplianceRegulatoryInformation/Guidances/UCM193282.pdf. Accessed October 30, 2015 .

46. Trujols J, Portella MJ. Not all PROMs reflect patients' perspectives. BMJ. 2013;346:f1552.

47. Trujols J, Portella MJ, Iraurgi I, Campins MJ, Siñol N, Cobos JPdL. Patient-reported outcome measures: are they patient-generated, patientcentred or patient-valued? J Ment Health. 2013;22(6):555-562.

48. Streiner DL, Norman GR. Health Measurement Scales: A Practical Guide to Their Devlopment and Use. 4th ed. Oxford: Oxford University Press; 2008.

49. Bowling A. Measuring Health: A Review of Quality of Life Measurement Scales. 3rd ed. Maidenhead: Open University Press; 2005.

50. Bharmal M, Payne K, Atkinson M, Desrosiers M, Morisky D, Gemmen E. Validation of an abbreviated Treatment Satisfaction Questionnaire for Medication (TSQM-9) among patients on antihypertensive medications. Health Qual Life Outcomes. 2009;7:36.

51. Quinlan P, Magid SK, O'Flaherty D, Peirce A, Stone PW. Patient satisfaction with medication management. J Nurs Care Qual. 2007;22(1): 34-39.

52. Blalock SJ, Patel RA. Drug therapy concerns questionnaire: initial development and refinement. J Am Pharm Assoc (2003). 2004;45(2): 160-169.

53. Okere AN, Renier CM, Morse J. Development and validation of a survey to assess patient-perceived medication knowledge and confidence in medication use. J Nurs Meas. 2014;22(1):1-13.

54. Krska J, Morecroft CW, Rowe PH, Poole H. Measuring the impact of longterm medicines use from the patient perspective. Int J Clin Pharm. 2014; 36(4):675-678.

55. Tran VT, Montori VM, Eton DT, Baruch D, Falissard B, Ravaud P. Development and description of measurement properties of an instrument to assess treatment burden among patients with multiple chronic conditions. BMC Med. 2012;10:68.

56. Reeve E, Shakib S, Hendrix I, Roberts MS, Wiese MD. Development and validation of the patients' attitudes towards deprescribing (PATD) questionnaire. Int J Clin Pharm. 2013;35(1):51-56.

57. Horne R, Faasse K, Cooper V, et al. The perceived sensitivity to medicines (PSM) scale: an evaluation of validity and reliability. Br J Health Psychol. 2013;18(1):18-30.

58. Horne R, Hankins M, Jenkins R. The Satisfaction with Information about Medicines Scale (SIMS): a new measurement tool for audit and research. Qual Health Care. 2001;10:135-140.

59. Jenkins L, Britten N, Stevenson F, Barber N, Bradley C. Developing and using quantitative instruments for measuring doctor-patient communication about drugs. Patient Educ Couns. 2003;50(3):273-278.

60. Linacre JM. Reliability and separation of measures. Available from: http://www.winsteps.com/winman/reliability.htm. Accessed October 25, 2015.

61. Morisky DE, Ang A, Krousel-Wood M, Ward HJ. Predictive validity of a medication adherence measure in an outpatient setting. JClin Hypertens. 2008;10(5):348-354.

62. Morisky DE, Green LW, Levine DM. Concurrent and predictive validity of a self-reported measure of medication adherence. Med Care. 1986; 24(1):67-74.

63. Horne R, Weinman J. Patients' beliefs about prescribed medicines and their role in adherence to treatment in chronic physical illness. J Psychosom Res. 1999;47(6):555-567.

64. Carter SR, Bulanadi MG, Katusiime B, Chen TF, Corlett S, Krska J. Comprehensibly measuring patients' subjective thoughts, feelings and experiences of living with medicines: the Living With Medicines Questionnaire (LMQ). Int J Clin Pharm. 2015;37:424-425.

65. Snyder ME, Pater KS, Frail CK, Hudmon KS, Doebbeling BN, Smith RB. Utility of a brief screening tool for medication-related problems. Res Social Adm Pharm. 2015;11(2):253-264. 
66. Dias-Barbosa C, Balp MM, Kulich K, Germain N, Rofail D. A literature review to explore the link between treatment satisfaction and adherence, compliance, and persistence. Patient Prefer Adherence. 2012;6:39-48.

67. Ridgeway JL, Egginton JS, Tiedje K, et al. Factors that lessen the burden of treatment in complex patients with chronic conditions: a qualitative study. Patient Prefer Adherence. 2014;8:339-351.

68. Gallacher K, Morrison D, Jani B, et al. Uncovering treatment burden as a key concept for stroke care: a systematic review of qualitative research. PLoS Med. 2013;10(6):e1001473.

69. Baker R. Development of a questionnaire to assess patients' satisfaction with consultations in general practice. Br J Gen Pract. 1990;40(341): 487-490.

70. Kinnersley P, Stott N, Peters T, Harvey I, Hackett P. A comparison of methods for measuring patient satisfaction with consultations in primary care. Fam Pract. 1996;13(1):41-51.

71. Ridd MJ, Lewis G, Peters TJ, Salisbury C. Patient-doctor depth-of-relationship scale: development and validation. Ann Fam Med. 2011;9(6):538-545.

72. Gatti ME, Jacobson KL, Gazmararian JA, Schmotzer B, Kripalani S. Relationships between beliefs about medications and adherence. Am J Health Syst Pharm. 2009;66(7):657-664.

73. Byer B, Myers L. Psychological correlates of adherence to medication in asthma. Psychol Health Med. 2000;5(4):389-393.
74. Scott IA, Gray LC, Martin JH, Pillans PI, Mitchell CA. Deciding when to stop: towards evidence-based deprescribing of drugs in older populations. Evid Based Med. 2013;18:121-124.

75. Thompson W, Farrell B. Deprescribing: what is it and what does the evidence tell us? Can J Hosp Pharm. 2013;66(3):201-202.

76. Tseng HM, Lee CH, Chen YJ, Hsu HH, Huang LY, Huang JL. Developing a measure of medication-related quality of life for people with polypharmacy. Qual Life Res. 2016;25(6):1295-1302.

77. Krska J, Morecroft C, Poole H, Rowe P. A novel instrument to measure medicines-related quality of life. Int J Clin Pharm. 2013;35:488.

78. Mokkink LB, Terwee CB, Knol DL, et al. The COSMIN checklist for evaluating the methodological quality of studies on measurement properties: a clarification of its content. BMC Med Res Methodol. 2010; 10(1):22.

79. Mokkink LB, Terwee CB, Patrick DL, et al. The COSMIN checklist for assessing the methodological quality of studies on measurement properties of health status measurement instruments: an international Delphi study. Qual Life Res. 2010;19(4):539-549.

80. Terwee CB, Mokkink LB, Knol DL, Ostelo RW, Bouter LM, de Vet HC. Rating the methodological quality in systematic reviews of studies on measurement properties: a scoring system for the COSMIN checklist. Qual Life Res. 2012;21(4):651-657.
Patient Related Outcome Measures

\section{Publish your work in this journal}

Patient Related Outcome Measures is an international, peer-reviewed, open access journal focusing on treatment outcomes specifically relevant to patients. All aspects of patient care are addressed within the journal and practitioners from all disciplines are invited to submit their work as well as healthcare researchers and patient support groups.

\section{Dovepress}

The journal is included in PubMed. The manuscript management system is completely online and includes a very quick and fair peer-review system. Visit http://www.dovepress.com/testimonials.php to read real quotes from published authors. 